\title{
Approaches to the Formulation of Russia's Technological Priorities
}

\author{
Alexey Ponomarev \\ Vice President for Strategy and Industry, Skoltech*; and Professor, Department of Educational \\ Programmes, HSE ISSEK**. E-mail: Ponomarev@skoltech.ru \\ Irina Dezhina \\ Head of Research Group on Science and Industrial Policy, Skoltech. E-mail: I.Dezhina@skoltech.ru
}

\begin{abstract}
* Skoltech - Skolkovo Institute of Science and Technology. Address: Skolkovo Innovation Center, 3 Nobel Str., Moscow Region, 143026, Russian Federation

** HSE ISSEK - Institute for Statistical Studies and Economics of Knowledge at the National Research University Higher School of Economics. Address: 11, Myasnitskaya str., Moscow, 101000, Russian Federation
\end{abstract}

\begin{abstract}
$\mathrm{T}$ he paper proposes a model for verifying ways to identify scientific-technological priorities in Russia and suggests instruments for their implementation and adjustment. Our model for the identification of priorities is based on Russia's socio-economic development goals, and takes into account the impact of different scientific and technological development scenarios on the implementation of models of socio-economic arrangement. Based on this logic, a group of technological priorities unchanged in face of the wider spectrum of national economic and social goals is suggested.

Global economic, social, and scientific-technological trends and their Russian projections are taken as exogenous

factors for selecting technological priorities. The suggested approach is based on the assumption that a new system of priorities should ensure support for implementing strategic development goals and tasks in the medium- and long term, and aims to help define these goals and tasks more accurately.

As a result, the paper identifies two groups of priorities. The first group outlines the already institutionalized areas of technological development while the second group outlines fields for institutionalization in the near future. The proposed logic is illustrated through an analysis of five global trends and their applications in Russia, and we highlight which technologies will be driven by these global trends.
\end{abstract}

Keywords: S\&T objectives; priorities; forecast; global trends; effects on the Russian economy; policy instruments

DOI: 10.17323/1995-459X.2016.1.7.15
Citation: Dezhina I., Ponomarev A. (2016) Approaches to the Formulation of Russia's Technological Priorities. Foresight and STI Governance, vol. 10, no 1, pp. 7-15. DOI: 10.17323/1995-459X.2016.1.7.15 
$\mathrm{T}$ he issue of target setting and selecting priority science and technology (S\&T) areas has been actively discussed in Russia for more than twenty years. Since the first approved list of priority areas and corresponding critical technologies of $1996,{ }^{1}$ the system of priorities at the national level has only undergone minor modifications. On the one hand, this reflects an objective situation where the importance of the broadly defined S\&T fields does not anticipate any rapid change. On the other hand, technological priorities within these areas have been extremely vague. Such a wide range of technologies is now classified as critical because it is impossible to effectively concentrate resources on individual technologies. Amid limited financial and human capital, the problem of identifying and structuring technological priorities is becoming ever more relevant. Another factor increasing the importance of rational selection is the changing foreign policy environment, which has an impact on opportunities and the ability to develop new technologies.

This article looks to describe a possible approach to selecting, substantiating, and supporting technological development priority areas in Russia. This is based on the assumption that the priorities system should be geared towards pre-existing strategic goals and national development objectives in the long- and mediumterm $^{2}$ and should contribute to the refinement of these goals and objectives. From a methodological perspective, global socio-economic and S\&T trends and the nature of their manifestation in the Russian context serve as input parameters, to be taken into account in the development of this system. The technological priorities thus formed are unchanged with respect to the broad spectrum of targeted socioeconomic development models in the country.

The paper is structured as follows. After defining the position of our approach among the numerous works on forecasting and selecting priority S\&T areas, it examines the parameters underlying the selection of technological priorities. Existing and future groups of priorities are then described in terms of their influence on intra-Russian projections of global socio-economic development trends. The results of the analysis form the basis for a possible classification of Russian priorities, which considers two parameters: global market potential and the manner of developing new technologies (Russian developments or borrowing from foreign sources). The conclusion finally delineates potential instruments to implement S\&T areas depending on their priority and suggests factors which could have an impact on the effectiveness of their use.

\section{Forecasting and selecting S\&T priorities}

The problem of identifying and selecting priority S\&T areas (critical technologies) and the associated 'future projection' (Foresight) has been studied for a long time by many researchers, continually looking to improve forecasting methods and expand the range of factors taken into account. We can date the emergence of this phenomenon back to the 1950s, when the RAND Corporation in the US developed the Delphi method to identify priority science and technology areas. Over the next two decades, Foresight studies were actively developed in four global centres: the US, Western Europe, Japan, and the USSR, and in the 1960s they started to improve the quantitative and qualitative methods used in technological Foresight studies. In the 1970s, Japan drafted its first national S\&T Foresight based on methods developed in the US; following Japan's experience, there was a spurt in mutual borrowings and adaptations of forecast and Foresight studies according to the specific characteristics of individual countries.

One of the first theoretical works on technology Foresight is arguably the 1984 study conducted by the British researcher/sociologist Ben Martin and John Irvine, which was later refined conceptually to accommodate the notion of 'technology Foresight' [Martin, 2010]. Martin and Irvine formulated the principles of technology Foresight, including the need for close coordination between prospective areas of scientific research and the development of approaches to identify strategic priorities. In other words, we should not view scientific and technological development in isolation from the socio-economic context [Coates et al., 2001].

An important aspect of identifying technological priorities is studying the mechanisms by which key technologies change (technological waves). Some of the best known among foreign specialists are works by Carlota Perez [Perez, 2002] and, in Russia, Sergey Glazev [Glazev, 1993], who has worked with his colleagues in this field for many years [Ivanov, 2015]. Scientific and technological development has been an important application of the socio-economic forecasting system, which was developed in the 1980s in the USSR and abroad [Bestuzhev-Lada, 1982].

After S\&T development forecasts for individual countries, comparative transnational forecast studies started to appear [Cuhls, Kuwahara, 1994]. Industry and corporate forecasts (Foresight studies) also started to gain popularity and undergo active development. It is worth noting that forecasts and Foresight studies are not equally popular in developed countries. For instance, in the US they are used predominantly to identify critical technologies [Wagner, Popper, 2003].

\footnotetext{
${ }^{1}$ Approved by the Government S\&T Policy Commission on 21 July 1996, no 2727p-P8, no 2728p-P8.

2 In particular documents such as the Concept of Long-term Socio-Economic Development of the Russian Federation for the Period up to the year 2020 (approved by Order no 1662-r of the Government of the Russian Federation dated 17 November 2008), the Strategy for Innovative Development of the Russian Federation 2020 (approved by Order no 2227-r of the Government of the Russian Federation dated 8 December 2011), and the National Security Strategy of the Russian Federation up to 2020 (approved by Decree no 537 of the President of the Russian Federation dated 12 May 2009).
} 
In recent years, substantial improvement has taken place in domestic forecast studies and in developing Foresight studies in Russia. Several theoretical works have been published [Gokhberg, 2014; Dynkin, 2011; Gaponenko, 2008], including some relating to specific sectors [Gokhberg, Filippov, 2014; Gaponenko, 2006]. Despite the successes achieved, no consensus has been reached as to how we should forecast future development as there is no one consolidated view regarding economic prospects. Much depends on the criteria initially stipulated, which, in turn, are defined by macro-factors, set in part by those who make strategic decisions at a specific moment in time.

Forecasting takes place in paradigms of economic and political cycles. New demands can spring up at any time and criteria are updated as appropriate. Thus, at the present time, import substitution in Russia is of such importance when selecting technology priorities that it should not be excluded from future iterative procedures to identify and select priorities.

\section{Methodological approaches to identifying priorities}

The methods used to define scientific and technological priorities can be reduced to a sequence of several recognized steps. One - studying global development trends on a macro-level, in the socio-economic and foreign political spheres, in fields such as manufacturing, information dissemination and use, and so on; Two - formulating goals for the country in terms of socio-economic development indicators and foreign political and economic objectives; Three - constructing structural policy scenarios and selecting S\&T priorities as components of these scenarios.

Further assessments of available financial, human, and other forms of resources are then carried out for each of the structural policy scenarios and, based on these findings approaches to change in the research and development (R\&D) sector are formulated. We note that a scientific development strategy proposing support of all fields of research without prioritization is not an option any longer despite renewed discussions from time to time about the need for extensive support for Russian theoretical studies [Smirnov, 2013].

The current R\&D structure in Russia highlights the fact that traditional scientific fields in Soviet times still dominate funding (physics, a number of engineering sciences), while support for medical and agricultural studies is still extremely modest [HSE, 2014, p. 107]. However, a variety of modern research areas are being implemented poorly in the engineering sciences. In particular, even in a dynamic field such as advanced production technologies, the competitiveness of research undertakings and certain Russian companies is low with localized achievements only in certain segments [Dezhina et al., 2015, p. 22]. The same can be said of photonics, where only laser research occupies a relatively strong position in Russia.

We believe that a more up-to-date system of scientific and technological priorities requires the formation of scenarios in which - if only approximately - the views of representatives from the state, sciences and businesses could be coordinated in terms of the aims of and opportunities for the Russian economy and $\mathrm{R} \& \mathrm{D}$ sector. The scenarios need to make provisions to distribute limited resources for technological development. They need to take into account three key parameters: the chosen system of national goals in corresponding fields; global as well as Russian trends in the political, socio-economic spheres where there is a high degree of uncertainty; and analytical results of international and Russian experience in S\&T development. These scenarios can only be built with certain assumptions regarding the dynamics of external factors that affect the S\&T sphere.

At the first stage, we need to identify those priorities, which do not change with respect to selecting development goals. The second stage involves a comparative assessment of the impact of resource distribution on the achievement of different groups of goals. The third stage consists of forming a complex variant of resource distribution for technological development in line with the system goals adopted by the relevant players. This paper will look at a possible algorithm for the first of the aforementioned stages.

\section{Groups of current and prospective technological priorities}

So far, Russia has adopted technological priorities, which can be conveniently categorized into three groups. The first is the already 'institutionalized' areas for technological development in the period up to 2020 and beyond. Here, one of the few guaranteed and accepted sources of funding is the defense and security sector, which expresses high demand for the development of certain technological areas. Aerospace and nuclear industries are two high-investment industries, which albeit limited in terms of commercial potential, fall into the same group. These are to a certain degree, derivatives of the national security sector.

Another long-term (up to 2030) de facto strategy is maintaining the share in the oil market amid conflicting trends caused by the nature of consumption, energy saving initiatives, and the structure of corresponding markets. This is a programmed, rather than institutionalized, demand for domestic R\&D and technology, which until recently was held back by the considerable supply of international oil-related services.

Finally, foreign political objectives and corresponding technological priorities linked to strengthening Russia's position in its own territories in the Far East and Arctic have also been set. 
The second group of priorities comprises areas planned for 'institutionalization' after 2015. The various policy documents and guaranteed funding identify pharmaceuticals, shipbuilding, and a number of other areas. However, in terms of the amount and effectiveness of support, it is still difficult to unambiguously categorize these priorities as institutionalized.

Changes in external conditions, including existing economic sanctions, call for the following structural changes:

- a fundamental expansion of the agricultural sector and food industry in order to satisfy the majority of domestic demand for food, including drinking water;

- import substitution of a significant proportion of end consumer goods - from light industry goods to resources for the housing and utilities sector;

- a qualitative improvement in the health care system and derivative pharmaceutical and medical industries;

- solutions to acute environmental problems in the most vulnerable regions and megalopolises.

With all the differences in the areas listed above, their development presents a demand for various technologies: ways to design and produce technological equipment and materials (to replace some of the imported next-generation equipment when expanding production), compact energy sources (to solve some environmental problems, for example, with transport), and a number of critical biotechnological developments, etc.

\section{Global trends and their Russian projections}

Continuous forecast and Foresight studies [Gokhberg, 2014; Berger, 2013; Dynkin, 2011] make it possible to identify global trends affecting S\&T development up to 2030. These include:

1. Regionalization of energy markets, expanding the use of alternative energy sources, improving energy saving methods while maintaining a significant share of hydrocarbons in global energy consumption, and a possible major change in the structure of hydrocarbon fuel supplied to the market;

2. Regionalization of goods production and reindustrialization of developed countries;

3. Change in the demographic structure of developed countries amid ageing populations;

4. Growing financial and intellectual stratification and the formation of new stable social strata;

5. New stage of digitalization in the social and economic spheres.

With reference to technological development, these trends require optimal environmental conditions to be maintained (including from the perspective of virology), as well as food security, balanced composition, number and geographical distribution of the population (including an understanding of rational employment), and localization and customization of production. Russian projects for each of these trends have their own specific features.

\section{Energy}

In the energy sector, a contraction in the hydrocarbon markets in the 2015-2018 period, extreme oil price volatility, a reduction in gas prices and an overall fall in energy resource trading margins is forecasted. From a macroeconomic perspective, this will help maintain relatively low ruble exchange rates. Due to the exhaustion of accessible deposits in Russia and the increasing dependence on imported extraction technologies and equipment, foreign currency revenue will suffer a significant decline.

As a result, the Russian oil extraction industry will show long-term demand - at least until 2030 for oil extraction technology and equipment for tight deposits. In view of the price instability and critical value of rational extraction margins to the budget, this demand should be for next-generation technologies allowing for the required level of profitability. The sanctions are making it more difficult to access foreign technologies of this type, and the fall in the rouble exchange rate is undermining the economic efficiency of the industry. As a result, we can expect a rise in demand for domestic extraction technologies the development of which will require predominantly theoretical research in specialized disciplines (geophysics, geochemistry, hydrodynamics, combustion physics, etc.) and the development of improvement technologies in materials engineering and general engineering.

According to experts, the trend of regionalizing energy markets will bring about demand for new technologies in South East Asia, including in China. With Russia's successes in corresponding research and technologies, it can be expected to compete with global oil services companies on these markets. Another favourable factor is the growing independence of the Chinese economy from the US. As such, in the medium-term the formation of a development programme for oil services and oil production engineering industries is very possible, including coordinated research (2015-2020) and the subsequent development of corresponding areas in 2020-2030.

A similar programme relating to hydrocarbon supplies is possible if the demand for new technologies from domestic extraction and oil services companies is realized and if there are calls for research institutions 
(prospecting and extraction), as well as for engineering companies (equipment production). Ultimately, demand for R\&D into technologies, equipment, and materials is important. Since there are few domestic developments in this sphere, active borrowing from global experience is needed for future development, especially in the period 2015-2020, as well as a roll-out of corresponding engineering projects in 2017-2025.

\section{Localization of production and reindustrialization}

Developed industrial countries are rolling out programmes to maintain or increase existing goods production. This process runs counter to the trends at the end of the 1980s when production was being moved to countries with cheaper labour [Dezhina, Ponomarev, 2014] and the 'stripped back growth' of whole regions of developed countries. External factors causing this trend include:

- the easier diffusion of technologies in the new digital space and the difficulty of monopolizing intellectual income from the use of such technologies (US, Europe);

- a path towards political and economic autonomy from former powers (China);

- the increased role of small and medium businesses as drivers of technological progress in the value added chain.

The scientific and technological basis for this trend is the accelerating development of key elements of modern production technologies using not only 'improvements', but also breakthrough developments that are based on dynamic research in modelling, optimization, big data analysis, nanotechnology, and materials engineering.

A key aspect of social and political demand for new production technologies in Russia and globally is linked to the possibility of decentralizing improvements to these technologies outside of hyper-industrialized regions, which allows employment problems to be solved and local economies to improve. This trend takes on particular importance in Russia due to the low level of mobility caused both by the economic and cultural climate. The transition to technologies allowing for the efficient customization of goods is giving rise to demand for applied research, as well as a broad spectrum of basic R\&D for creating new materials and improving engineering design models. Advanced production technologies respond to an extremely broad array of challenges - from the stratification of society to the digitalization of socioeconomic spheres.

In the Russian economy, the demand for $\mathrm{R} \& \mathrm{D}$ in new production technologies is in turn driving engineering, including engineering geared towards the production of equipment for commodity industries. However, corresponding technological priorities can only be formulated by looking for common ground in the requirements of a wide range of major customers, including the oil and gas sector, space and nuclear industries, and the regional and local industries that rely on small and medium businesses.

Priorities can be implemented through a system of projects. These projects create demand for:

- in the medium term - for initial orders from engineering for the oil and gas industry (and power engineering in general) and the aerospace and nuclear industries;

- supply (willingness to engage in development and production) predominantly from mediumsized companies and consortiums of potential equipment producers and a wide range of small and medium materials producers.

Taking into account the disparate nature of corporate and state investment in advanced production technologies in developed countries and the opportunities for the Russian economy, a niche may be created by a number of measures specific to Russia. Primarily this involves stimulating in-depth, 'noncompetitive', long-term cooperation between potential producers and 'initial customers'. Such cooperation can take place through vertical consortiums of major players, which may be the end-consumers of new technologies, potential developers and producers of technologies and materials, or research structures. A key role can also be played by the support offered for cooperation with 'initial customers' to develop the very best universal technological specifications for the products of potential suppliers of technologies, equipment, and materials. This makes it possible to establish a relatively large initial portfolio of orders and to concentrate small-scale initial resources on developing new products.

The specific form of cooperation might be between, for instance, companies in the space, nuclear and engineering industries agreeing to a set of specifications on new domestic CAD, CAE, and CAM blocks. Ultimately, we should not disregard approaches such as 're-engineering' which looks to make maximum use of legal (licensed) copying and borrowing of technologies, followed by subsequent localization and redevelopment. This approach requires the concentration of various types of resources in multidisciplinary centres where there is a high level of scientific potential and a profile, which are willing and motivated to engage in significant medium-term adjustments.

\section{Demographic changes}

The change in the size and structure of Russia's population has manifested itself amid slight growth in the duration of the population's working life and a delay among youth in entering the labour market. Growth 
in the birth rate in the last decade has predetermined the labour dynamics in Russia for the period up to 2030. Those industries of the economy showing demand for low-qualified workers have until recently absorbed predominantly migrants, following partial naturalization. It is difficult to predict the shortterm development of trends such as the changing structure of employment and motivations, migrant flows, quality of life and workforce distribution, formal and concealed unemployment, labour supply and demand in regions, and structural imbalances in personnel training.

At the same time, there is a clear trend of an ageing population, which is increasing demand for employment in line with age peculiarities and for specific goods and services. Particular demands are being made on the health care system to support the activity of the elderly. Modern biomedical research, which needs far more investment than the Russian R\&D sector, does not offer any hope of competitive Russian methods and procedures emerging in the medium term. In this time frame, the Russian health care sector needs to borrow the latest methods and solutions, rather than relying on local breakthroughs. Around the world, advanced biomedical research is now conducted on neurotechnologies and genetics. It is reflected in some of the largest foreign projects of recent years, funded by both civilian and military sources. In Russia, however, extremely modest sums are channelled into areas that will be key in overcoming the demographic and migration problems facing the country.

This trend is stimulating the development of several areas in which Russia has certain initial resources and qualities. These include:

- digital technologies to expand virtual interaction and carry out a broad spectrum of household tasks for individuals with limited physical capabilities;

- advanced manufacturing technologies calling for part-time and remote working;

- biomedical technologies for health care purposes;

- agricultural technologies, the importance of which will increase as the employment structure in Russia changes and demands increase regarding food quality.

Thus, demographic trends create demand primarily for certain types of advanced biomedical, advanced production, and digital technologies.

\section{Stratification of the population and new stratification}

The Russian projection of this trend manifests in the growing monopolization of the economy, worsening business conditions for SMEs, and deepening pay gap between high and low earners at major companies. Intra-country differentiation is growing and economic growth prospects in many regions remain hazy.

The digital industry could provide a response to these challenges in part by creating the necessary conditions to earn through digital networks. The development of digital technologies is leading to the emergence of next-generation hardware, including optoelectronics and quantum data processing. At the same time, there is growing demand for advanced manufacturing technologies as one of the mechanisms to offset regional imbalances, which helps distribute employment and create jobs with low investment barriers.

\section{Digitalization of society and the economy}

This trend is widely discussed in the international and Russian professional sphere as well as in many social organizations. A whole series of forecasts have been prepared in this sphere [Naional Research Council, 1998; Lane, Kalil, 2005; National Photonics Initiative, 2013] with a particular focus on photonics and new production technologies.

Overall, Russia is following the trend's global trajectory, but with some slight differences. These primarily concern the low market volumes, modest expertise in hardware and devices, and the lack of major software developments. The professional community recognizes the productivity of concentrating efforts in certain mainstream areas in this field to create globally competitive and compatible modules and components. All of this helps to stimulate R\&D in self-learning systems (next-generation artificial intelligence), hardware (in particular, optoelectronic devices and devices based on new quantum materials), data analysis, and the development of virtual environments.

\section{Formation of a Russian system of technological priorities}

To identify those technologies that could be justifiably developed from the perspective of the goals and objectives in national structural policy and Russian projections of global socio-economic trends, we need to start by examining existing technological priority systems. Global experience in identifying priority S\&T areas shows that they are similar in many countries, despite their different levels of industrial development. As a rule, these priorities include:

- biotechnology;

- next-generation information technologies; 
- energy and energy saving technologies;

- new materials.

For Russia, this traditional list is confined to certain niches in mainstream global priorities where breaking into the international scene and achieving global competitiveness is possible, but where the research base is lacking amid growing demand from several sectors that are critical to national goals. The priorities identified in this way can be broken down further to technological areas of the following types:

- those with potential for independent development (limited number of areas);

- those operating through 'borrowing and development';

- those which are subsidiary to the development of various sectors of the Russian economy, which are dependent on searching for, locating and, where necessary, adapting foreign technologies.

We propose classifying the analyzed technologies analysed in a global context according to two parameters: the level (areas with global market potential, or taking advantage of demand but technologically backward) and methods of development (domestic or borrowed developments). A possible structure of technological priorities is given in Table 1. Advanced production, information and communication, and biotechnologies are classified as potentially competitive technologies on global markets. The second group of priority technologies includes energy and agricultural technologies, demand for which comes from the relevant sectors even when there is significant backwardness in the sector. In all of these the 'new materials' factor is present, which is hard to view separately in view of the diversity of subjects that it covers. The connection between materials engineering and other areas in this structure appears to be more rational.

\section{Instruments and opportunities to implement new Russian priorities}

Russia and the rest of the world have now amassed an abundant toolkit to implement priority S\&T areas. In order to identify the most effective instruments, we propose identifying S\&T priorities, which have been coordinated with structural priorities for economic development. We must also identify the priorities, which have not yet been recognized as breakthrough areas where retention of technological receptiveness and ensuring a certain level of competence are important. In the latter case, resources need to be invested to develop expertise that could be in demand in the next 10-15 years when defining new technological areas of structural priorities.

For S\&T priorities coordinated with structural and economic priorities, instruments to support companies, which establish fruitful long-term cooperation (consortiums) to implement key programmes on a national scale are the most effective. Through these initiatives, the following practical measures may be adopted:

- raising initial orders from key Russian companies for globally competitive next-generation technologies;

- setting up consortiums on a private or public-private basis to develop such technologies;

- developing and implementing a coordinated research programme focused on these developments.

The main elements of development and implementing this type of initiatives might be:

- preparing detailed analytical reports on the state and development of areas, coordinating them with key companies (potential producers and consumers) and arranging expert assessments by leading global specialists;

- setting up scientific and technological councils as 'collective general designers' and having them prepare coordinated interdepartmental R\&D programmes;

- setting up consortiums and coordinating technological objectives and work plans between them and potential customers;

- raising initial orders from groups of core consumer companies;

- making changes to state programmes;

- developing (where required) additional mechanisms - legislative, normative, administrative - to stimulate work through initiatives.

Technological receptiveness requires a different approach based on an analysis of mainstream areas in the global S\&T landscape by international experts and consultants based in Russian research institutions and which would include the reorientation of connected work and the formation of new research groups. This needs to be then followed with the development of mechanisms to reorient these groups to new areas, including instruments to change their financing, attract foreign partners, and support academic mobility. A system of information sharing with industry and stimulating small innovative businesses are other important elements of technological receptiveness.

Finally, the human factor has to be taken into account. Selecting and implementing all types of priorities involves overcoming low motivation among the directors of all types of companies, authorities, and a significant number of scientific and technological organizations to engage in responsible forward planning 
Table 1. An option for the technological priorities typology and ways of developing them

\begin{tabular}{|c|c|c|}
\hline Technology & Own development & Borrowing and development \\
\hline \multicolumn{3}{|c|}{ Technologies securing global market positions } \\
\hline $\begin{array}{l}\text { Prospective production } \\
\text { technologies }\end{array}$ & $\begin{array}{l}\text { - Advanced design system modules based on areas } \\
\text { such as data optimization and analysis for emerging } \\
\text { engineering industries (assuming progress in } \\
\text { streamlining the requirements of some of the largest } \\
\text { Russian consumer companies) } \\
\text { - Certain types of materials, primarily composite and } \\
\text { metallic materials, for advanced, predominantly } \\
\text { additive production technologies, for the aerospace, } \\
\text { nuclear and defense industries, gradually expanding } \\
\text { the range in cooperation with drivers of development } \\
\text { in other industries }\end{array}$ & $\begin{array}{l}\text { - Equipment for additive technologies } \\
\text { - Individual design system modules, especially } \\
\text { expensive ones or those affected by supply } \\
\text { restrictions to Russia, which are highly likely }\end{array}$ \\
\hline $\begin{array}{l}\text { Next-generation } \\
\text { information and } \\
\text { communication } \\
\text { technologies }\end{array}$ & $\begin{array}{l}\text { - Technologies used to develop new quantum materials } \\
\text { and devices such as sensors to control spaces and } \\
\text { production processes and next-generation data } \\
\text { processing devices to occupy specialized niches and } \\
\text { acquire critical expertise } \\
\text { - Photoelectronic communications and data processing } \\
\text { technologies } \\
\text { - Big data analysis technologies to control spaces, } \\
\text { technological processes and solve socio-economic } \\
\text { problems } \\
\text { - Certain areas of imitation modelling and } \\
\text { development of computer power for this purpose }\end{array}$ & $\begin{array}{l}\text { - 'Pilotless' ('unmanned') algorithms for } \\
\text { vehicles and production } \\
\text { - Diagnostic systems } \\
\text { - Broad class of modelling tasks and } \\
\text { development of computer power }\end{array}$ \\
\hline $\begin{array}{l}\text { Biotechnology, including } \\
\text { neuro- and cognitive } \\
\text { technologies }\end{array}$ & $\begin{array}{l}\text { - Data analysis technologies, primarily for genome } \\
\text { (postgenome) research and neurotechnologies; } \\
\text { certain diagnostics technologies } \\
\text { - Certain areas in neurotechnology } \\
\text { - Virology technologies }\end{array}$ & $\begin{array}{l}\text { - Broad class of cell therapy technologies } \\
\text { - Diagnostics } \\
\text { - Certain areas in neurotechnology and } \\
\text { cognitive technologies }\end{array}$ \\
\hline \multicolumn{3}{|c|}{ Technologies taking advantage of domestic demand amid serious technological backwardness } \\
\hline Energy technologies & $\begin{array}{l}\text { - Development and optimization of technologies } \\
\text { used to extract hydrocarbons from unconventional } \\
\text { reserves linked to the specifics of Russian deposits } \\
\text { (modelling processes in complex deposits, geological } \\
\text { prospecting technologies) } \\
\text { - Technologies to optimize consumption in energy } \\
\text { networks }\end{array}$ & $\begin{array}{l}\text { - Development of certain energy storage } \\
\text { technologies and devices } \\
\text { - Certain oil extraction technologies } \\
\text { (technologies based on physics and } \\
\text { chemistry to raise the oil recovery ratio etc.) }\end{array}$ \\
\hline Agricultural technologies & $\begin{array}{l}\text { - Use of biomedical technology and pharmaceutical } \\
\text { achievements in agriculture }\end{array}$ & $\begin{array}{l}\text { - Wide range of productivity-enhancing } \\
\text { technologies, predominantly through green' } \\
\text { methods } \\
\text { - Mastery of new areas (aquaculture, new } \\
\text { methods in livestock rearing, processing and } \\
\text { storage) } \\
\text { - Range of technologies providing the } \\
\text { population with clean water }\end{array}$ \\
\hline
\end{tabular}

in core fields. Administrative and technological stagnation in many industrial companies, increasingly prohibitive regulation in science and other spheres, and the lower quality of life are making Russia less appealing to leading and dynamic researchers and developers as well as demotivating scholars with respect to foreign collaboration. At the same time, the potential to develop the R\&D sector is far from absent. In addition to a greater influx of young people into the R\&D sector, in a number of cases there are still mutually beneficial research connections with organizations in niche fields (and these connections are even expanding), which are important in terms of acquiring, maintaining and developing absent expertise.

The short-term objective is to concentrate on building up a critical mass of qualified and dynamic specialists and to implement the maximum number of priorities mentioned above, ensure their institutionalization, and address related challenges (longevity of programmes and projects, rational funding, standards, regulation, access to infrastructure, etc.) A complex, but necessary aspect, consists of identifying sufficiently charismatic leaders for individual projects and granting them the necessary resources and authority. It would also be advisable to implement administrative decisions to start longterm technological partnership programmes with major - including state-owned - companies. The falling federal allocations to $R \& D$ requires sensible 'redistribution' decisions across all spheres of $R \& D$, an inventory of the investment programmes of state-owned companies, and the improvement of principles and regulation for technology procurement. 


\section{Conclusions}

The methodical approaches presented in this paper help us to identify technological trends which are worth developing in view of the challenges faced in fields such as energy and energy saving, the geographical distribution of goods production, demographic structure and the ageing population, financial and intellectual stratification, and the digitalization of socio-economic spheres. The technological priorities that were examined, however, do not change according to the different possible socio-economic structure models in the country.

Among the technological priorities offering responses to these challenges are next-generation information and communication technologies, advanced production technologies, and bio-, neuro-, cognitive, energy and agricultural technologies. Each of these spheres is broken down into narrower fields; the latter can be developed either through domestic R\&D or the borrowing of technologies.

The selection of policy instruments depends on whether the identified field is an institutionalized priority area or an area requiring support to maintain its technological receptiveness. Among the measures of particular importance, it is worth noting financial, organizational and regulatory measures, as well as more delicate instruments that motivate actors to develop and use domestic technologies.

The assumptions, approaches, and assessments made do not claim to be comprehensive. This paper has presented a model and an arguably credible approach towards identifying technological priorities as well as possible mechanisms to adjust and implement the latter.

\section{References}

Berger S. (2013) Making in America. From innovation to market, Cambridge, MA: MIT Press.

Bestuzhev-Lada I. (1982) Rabochaya kniga po prognozirovaniyu [Working book on forecasting]. Moscow: Mysl' (in Russian).

Coates V., Farooque M., Klavans R., Lapid K., Linstone H.A., Pistorius C., Porter A.L. (2012) On the Future of Technological Forecasting. Technological Forecasting and Social Change, vol. 67, no 1, pp. 1-17.

Cuhls K., Kuwahara T. (1994) Outlook for Japanese and German Future Technology, Comparing Technology Forecast Surveys, Heidelberg: Physica-Verlag.

Dezhina I., Ponomarev A. (2014) Perspektivnye proizvodstvennye tekhnologii: novye aktsenty v razvitii promyshlennosti [Advanced Manufacturing: New Emphasis in Industrial Development]. Foresight-Russia, vol. 8, no 2, pp. 16-29.

Dezhina I., Ponomarev A., Frolov A. (2015) Perspektivnye proizvodstvennye tekhnologii v Rossii: kontury novoi politiki [Advanced Manufacturing Technologies in Russia: Outlines of a New Policy]. Foresight-Russia, vol. 9, no 1 , pp. 20-31.

Dynkin A. (ed.) (2011) Strategicheskii global'nyi prognoz 2030. Rasshirennyi variant [Strategic global forecast 2030. Expanded version], Moscow: Magistr (in Russian).

Gaponenko N. (2008) Forsait: teoriya, metodologiya, opyt [Foresight: theory, methodology, experience], Moscow: YUNITI-DANA (in Russian).

Gaponenko N. (ed.) (2006) Nanotekhnologii: Forsait [Nanotechnologies: Foresight], Moscow: Sovremennaya economika i pravo (in Russian).

Glazyev S. (1993) Teoriya dolgosrochnogo tekhniko-ekonomicheskogo razvitiya [Theory of the long-term technicaleconomic development], Moscow: Vladar (in Russian).

Gokhberg L. (ed.) (2014) Prognoz nauchno-tekhnologicheskogo razvitiya Rossii: 2030 [Russian S\&T Foresight 2030] (ed. L. Gokhberg), Moscow: RF Ministry of Education and Science, NRU Higher School of Economics (in Russian).

Gokhberg L., Filippov L. (eds.) (2014) Prognoz nauchno-tekhnologicheskogo razvitiya Rossii: 2030. Energoeffektivnost' $i$ energosberezhenie [Forecast of scientific-technological development of Russia: 2030. Energy efficiency and energy saving], Moscow: RF Ministry of Education and Science, NRU Higher School of Economics (in Russian).

HSE (2014) Indikatory nauki: 2014. Statisticheskii sbornik [Science and Technology Indicators in the Russian Federation: 2014. Data Book], Moscow: HSE (in Russian).

Irvine J.M., Martin B.R. (1984) Foresight in Science: Picking the Winners, London: Pinter.

Ivanov V. Innovatsionnaya paradigma XXI [Innovation paradigm XXI], Moscow: Nauka (in Russian).

Lane N., Kalil T. (2005) The National Nanotechnology Initiative: Present at the Creation. Issues in Science and Technology, Summer 2005, pp.49-55.

Martin B.R. (2010) The Origins of the Concept of 'Foresight' in Science and Technology: An Insider's Perspective. Technological Forecasting and Social Change, vol. 77, no 9, pp.1438-1447.

National Photonics Initiative (2013) Lighting the Path to a Competitive Secure Future. Available at: http://spie.org/ Documents/AboutSPIE/NPI_Launch_Slides_23_May_2013.pdf, accessed 24.06.2014.

National Research Council (1998) Harnessing Light: Optical Science and Engineering for the 21st Century, Washington, D.C.: National Academy Press.

Perez C. (2002) Technological Revolutions and Financial Capital: The Dynamics of Bubbles and Golden Ages, London: Edward Elgar.

Smirnov S. (2013) Kakaya nauka nam nuzhna: mnenie akademikov [Which science we need: Opinion of academicians]. Nauka i Zhizn', 09.04.2013. Available at: http://www.nkj.ru/news/21988/, accessed 24.06.2015 (in Russian).

Wagner C., Popper S. (2003) Identifying critical technologies in the United States: A review of the federal effort. Journal of Forecasting, no 22 (2/3), pp. 113-128. 